\title{
Color-coded duplex sonography vs. 3.0 Tesla magnetic resonance angiography for detection of intracranial stenosis of the internal carotid artery: A prospective cohort study
}

\author{
LU XIAO, WEN CHU and HUA WANG
}

Department of Ultrasound, Luoyang Central Hospital Affiliated to Zhengzhou University, Luoyang, Henan 471000, P.R. China

Received March 31, 2019; Accepted September 26, 2019

DOI: $10.3892 /$ etm.2019.8255

\begin{abstract}
Hemodynamic changes may provide important information for clinical decision-making in internal carotid artery (ICA) stenosis. The degree of stenosis is responsible for the hemodynamic changes. For detection of intracranial stenosis, each diagnostic method has its own advantages and disadvantages. The goal of the present study was to compare the sensitivity and accuracy of color-coded duplex sonography with that of magnetic resonance angiography (MRA) for the detection of intracranial stenosis. Patients with 3 vessels and/or left stem coronary artery disease were subjected to transcranial and extracranial color-coded duplex sonography $(n=998)$, MRA $(n=998)$ and invasive catheter angiography $(n=939)$. The degree of stenosis was defined according to the Warfarin-Aspirin Symptomatic Intracranial Disease methodology. $\mathrm{A} \geq 50 \%$ reduction in artery diameter was considered as a positive obstructive lesion. The benefits of each imaging method were assessed by clinical decision-making analysis. Color-coded duplex sonography and MRA, had sensitivities of 0.935 and 0.957 and accuracies of 0.92 and 0.974 , respectively, when using invasive catheter angiography as a gold standard. The number of false-positive obstructive lesions detected by MRA was significantly higher than that for color-coded duplex sonography (53 vs. $13, \mathrm{P}<0.0001)$. Color-coded duplex sonography was able to detect an obstructive lesion in one single image for ICAs with $\geq 57 \%$ stenosis, while MRA was only capable of detecting an obstructive lesion in one single image for ICAs with $\geq 80 \%$ stenosis. In conclusion, color-coded duplex sonography is a reliable method for the detection of intracranial stenosis in patients with coronary artery disease.
\end{abstract}

Correspondence to: Dr Wen Chu, Department of Ultrasound, Luoyang Central Hospital Affiliated to Zhengzhou University, 288 Zhongzhou Middle Road, Luoyang, Henan 471000, P.R. China E-mail: christophersteinhbn@yahoo.com

Key words: clinical decision-making, color-coded duplex sonography, coronary artery disease, intracranial stenosis, invasive catheter angiography, magnetic resonance angiography

\section{Introduction}

Intracranial stenosis may result in ischemic infarction (1) and is associated with a risk of ischemic stroke (2). Extracranial and intracranial carotid artery stenosis is common among symptomatic patients in China (3). Autopsy studies have proved that cerebral vascular occlusion is the major cause of stroke (4). The most common location for intracranial stenosis is the internal carotid artery (ICA) (5) and it is accessed by evaluation of the degree of luminal stenosis on angiography (6). Hemodynamic changes may provide important information for clinical decision-making, but the degree of ICA stenosis, which is responsible for hemodynamic changes, may not be properly determined by using imaging modalities (7).

Application of suitable diagnostic methods for intracranial stenosis remains challenging (8). The diagnostic methods currently used for detection of intracranial stenosis are transcranial Doppler ultrasound (9), digital subtraction angiography, high-resolution magnetic resonance imaging (MRI) (10), conventional catheter angiography (9), CT angiography (10) and magnetic resonance angiography (MRA) (5). CT angiography is less prone to movement artifacts within the blood vessels and has a shorter signal-to-noise ratio than MRA, but has the risk of degradation of image quality and limitations of post-processing artifact interpretations (9). High-resolution MRI is suitable for diagnosis of the C1, C3 and C5 segments only due to the inherent signal-intensity loss of parallel imaging in the other segments (5) but it cannot be applied for patients with pacemakers (9). MRA facilitates the determination of stenosis grade (5). Digital subtraction angiography is usually performed after MRA (5). Transcranial Doppler ultrasound is only effective when the blood flow pattern is abnormal (5). Overall, each diagnostic method has its own advantages and disadvantages.

The purpose of the present prospective study was to compare the sensitivities and accuracies of color-coded duplex sonography with those of MRA for the detection of intracranial stenosis while using conventional catheter angiography as a reference standard in Chinese patients with coronary artery disease.

\section{Materials and methods}

Inclusion/exclusion criteria. Patients aged $\geq 18$ years with angiographic confirmation of 3 vessels and/or left stem coronary artery disease, as well as symptoms of a transient 
ischemic attack and cerebral ischemia with/without neurologic deficits were included in the study. Only patients with isolated intracranial stenosis were included. Patients who had impairments of the brain, spinal cord or nerve function, or diseases associated with functional deterioration of organs (according to clinical diagnostic parameters and MRI) were excluded from the study. Patients with inadequate image quality for interpretation were also excluded from the analysis. Prior to transcranial diagnosis, plaques (atherosclerotic lesions) present in the extracranial vessels were excluded by standard extracranial color-coded duplex sonography.

Color-coded duplex sonography. All color-coded duplex sonographies were performed using 19" LED up and down $90^{\circ}$ foldable color-duplex ultrasound systems equipment (LOGIQ e; GE Healthcare) with a 2.4-10.0 MHz linear array transducer (9L-D; GE Healthcare) for the extracranial examination and a 4-10 MHz phased array (PA6-8 H46701J; GE Healthcare) for the transtemporal examination.

Transcranial color-coded duplex sonographies were performed with a $4 \mathrm{MHz}$ center transmit frequency in color mode, linear post-processing, highest transmit power, at intermediate resolution and the pulse repetition frequency for the central focal zone. The gain of color was maintained as per the acoustic bone window of the proband to avoid colored speckles outside the borders of vessels. The gate of Doppler was set at $5 \mathrm{~mm}$ and $0^{\circ}$ angles in all the measurements of blood flow. If the angle was $<60^{\circ}$, it was corrected in the segment of the arteries with a minimum of $20 \mathrm{~mm}$. Transcranial color-coded duplex sonographies were started from the axially-oriented transtemporal approach. The butterfly-shaped hypoechogenic mesencephalic brainstem was located. As illustrated in Fig. 1, a P1 segment (indicated in red) and P2 segment (red and blue) were identified for the assessment of the posterior cerebral artery. The transducer was moved slightly upwards, and the M1 segment (indicated in red) of the middle cerebral artery and anterior cerebral artery (indicated in blue) was visualized. Finally, the transducer was moved slightly toward the posterior part of the brain and a cross-sectional view of the terminal ICA (the C1 segment) was visualized. The transducer was made perpendicular in an anti-clockwise direction towards the frontal planes. During the anterior scanning, the $\mathrm{C} 1 \mathrm{segment}$ (indicated in red) of the ICA, the A1 segment of the anterior cerebral artery and the M1 segment of the middle cerebral artery were visualized. Slightly frontal towards the posterior frontal plane, the basilar artery was visualized at the top, and the posterior cerebral arteries and C5 segment (blue color) near the carotid canal were also visualized. Subsequently, in a slightly lateral view, the C4 segment was identified (blue color; Fig. 1) (1).

For the siphon segments, the axial mesencephalic image plane was preferred. For the diagnosis, the coronal planes were used for the middle cerebral artery. The M1 segment in the middle cerebral artery and the carotid siphon $\mathrm{C} 1$ and $\mathrm{C} 5$ segments were diagnosed on the bilateral sides (1).

The end-diastolic blood flow velocities, peak systolic blood flow velocities and mean blood flow velocities were recorded. The pulsatility index, resistance index and C1/ICA index were calculated for each vessel segment as per Equations i, ii and iii (1).
Pulsatility index $=\frac{\text { Peak systolic blood flow velocity }- \text { End diastolic blood flow velocity }}{}$

Resistance index $=\frac{\text { Peak systolic blood flow velocity- End diastolic blood flow velocity }}{\text { Peak svstolic blood flow velocitv }}$

$$
\frac{\mathrm{C} 1}{\mathrm{ICA}} \text { index }=\frac{\text { Mean blood flow velocity of C1 }}{\text { Mean blood flow velocity of the ICA }}
$$

MRA. 3.0 Tesla MRI equipment (GE Healthcare) was used to visualize the cervical intracranial artery, petrous intracranial artery, cavernous intracranial artery, supraclinoid portions, anterior cerebral artery, segment A1, segment A2, middle cerebral artery, segment M1, segment M2, posterior cerebral artery, segment P1, segment P2, intracranial vertebral artery, the proximal basilar artery and distal basilar artery. The field of view was as small as possible over the middle cerebral artery and $512 \times 512 \mathrm{~mm}^{2}$ matrices. T1-weighted imaging (T1WI) was performed with a repetition time/echo time (RT/ET) of $565 / 15.79$ msec, T2WI with fast-spin-echo array coil spatial sensitivity encoding and a RT/ET of $2,884 / 50 \mathrm{msec}$, proton density-weighted imaging with a RT/ET of 6,241/32.6 msec and short T1 inversion recovery imaging with a RT/ET of $3,701 / 56.3 \mathrm{msec}$ were acquired for determination of the middle cerebral artery lumen diameter. A total of $16 \mathrm{MR}$ slices $(2 \mathrm{~mm}$ slice thickness $\mathrm{x} 0.5 \mathrm{~mm}$ slice interval) with 6-fold signal averaging including stenosis were acquired (11).

Invasive catheter angiography. The patients who exhibited stenosis on color-coded duplex sonography and/or MRA were subjected to invasive catheter angiography. Femoral punctures were given to patients by injection of vehicles using Ultrasvist (Bayer Healthcare AG). In late venous phase with standard anteroposterior, lateral and oblique images were acquired with $1,024 \times 1,024$ matrix, pixel size of $0.21 \times 0.21$ and a field of view of $22 \mathrm{~cm}$ with $5 \mathrm{ml} / \mathrm{sec}$ of the contrast agent inflow rate (12).

Image analysis. All Digital Imaging and Communications in Medicine files were uploaded onto a workstation (version 4.0; GE Healthcare). The artery diameter of the maximal stenosis side and non-stenosis region were measured. The proximal and distal views were examined. The analysis was performed orthogonal to the long axis of the artery and the stenosis was evaluated in segment M1 for comparison (12). The degree of stenosis was considered as per Equation iv, in accordance with the Warfarin-Aspirin Symptomatic Intracranial Disease methodology (9) under consultation of a neuroradiologist (25 years of experience).

$\%$ Stenosis $=\left[1-\frac{\text { Artery diameter of the maximal stenosis side }}{\text { Artery diameter of the non-stenosis region }}\right] \times 100$

A reduction in diameter of $\geq 50 \%$ of the artery was considered as a positive obstructive lesion; otherwise, the diagnosis of obstructive lesion was negative (13).

Advantage score analysis. The advantages of each of the modalities adopted were evaluated by clinical decision-making analysis. The advantage score of each diagnostic method adopted was evaluated as per Equations v and vi (14):

Advantage score $=$

Number of patients with a true positive obstructive lesion Number of patients subjected to diagnosis

( $\frac{\text { Number of patients with false positive stenosis }}{\text { Number of patients were subjected to diagnosis }} \mathrm{x}$ Risk of overdiagnosis) 


$$
\text { Risk of overdiagnosis }=\frac{\text { Threshold probability }}{1-\text { Threshold probability }}
$$

The invasive catheter angiography was used as the gold standard to determine the true- and false-positive rates of the other methods.

Cost. The cost of each diagnostic modality was calculated.

Statistical analysis. InStat, version 3.0 for Windows (GraphPad Inc.) was used for statistical analysis. Categorical data were compared using the Wilcoxon matched-pairs test (12). All variables were considered significant at a $99 \%$ confidence level. The mean reader difference values were calculated for each diagnostic method adopted to assess interobserver reliability (15). Continuous data were compared using the Friedman test followed by the Nemenyi test (considering a critical value $q$ of $>3.314$ as indicative of significance). The cost was analyzed by one-way analysis of variance (16) followed by the Tukey-Kramer multiple-comparisons test.

\section{Results}

Patient characteristics. Between January 2015 and December 2017, a total of 1,005 patients with 3 vessels and/or left stem coronary artery disease were available at Luoyang Central Hospital Affiliated to Zhengzhou University (Luoyang, China) and the referring hospitals. All patients were subjected to interview (panel of a cardiologist, a neurologist and a physician of the institute, all with a minimum of 3 years of experience) and the cardiovascular risk of each patient was estimated based on demographic, clinicopathological and laboratory data (Table I). Among those patients, three had impairments of the brain, one had impairments of the spinal cord, one had impairments of nerve function, one had diseases associated with functional deterioration of organs and for one patient, the image quality of color-coded duplex sonography was inadequate for interpretation. Therefore, these patients were excluded from the analysis. A total of 998 neurologically asymptomatic patients were subjected to color-coded duplex sonography and MRA. The flow diagram for inclusion of patients in the present study is provided in Fig. 2.

Obstructive lesions of the ICA. In the transcranial and extracranial portions, stenosis was detected in 909 patients by color-coded duplex sonography and in 939 patients by MRA. Therefore, a total of 939 patients were subjected to invasive catheter angiography. Invasive catheter angiography was superior in the detection of stenosis compared with color-coded duplex sonography $(\mathrm{P}<0.0001 ; \mathrm{q}=4.144)$ and MRA $(\mathrm{P}<0.0001$; $\mathrm{q}=7.301)$. The results of the different diagnostic modalities regarding evaluation of obstructive lesions are provided in Table II. The pulsatility index, resistance index and C1/ICA index were higher for obstructive lesions than for normal lesions $(\mathrm{P}<0.0001$ for all; data not shown). The intracranial stenosis in the other intracerebral arteries were mostly found in M1 and M2 segments of middle cerebral arteries, the vertebral artery and the anterior cerebral artery. The distribution of intracranial stenosis in the other intracerebral arteries assessed is presented in Table III.
Table I. Demographic and clinicopathological characteristics and laboratory parameters of the patients enrolled $(n=998)$.

Item Value

Ethnicity

Han Chinese

$912(92)$

Mongolian

Tibetan

Age (years)

Range

Mean \pm SD

$59.85 \pm 8.89$

Sex

Male

Female

Blood pressure $(\mathrm{mmHg})$

Diastolic

$86.52 \pm 5.45$

Systolic

$135.12 \pm 14.12$

$201(20)$

Time from onset of transient

$41.12 \pm 5.45$

ischemic symptoms (days)

Transient ischemic symptoms

Mild paralysis in side of body

55 (6)

Garbled speech

$101(10)$

$52(5)$

Double vision

$173(17)$

Dizziness

$203(20)$

Headache

173 (17)

Dyslipidemia

308 (31)

$545(55)$

145 (14)

$\geq 30$ (obese)

$790(79)$

145 (15)

63 (6)

Previously

Currently

$888(89)$

65 (6)

45 (5)

38 (4)

21 (2)

$23.12 \pm 1.25$

5 (1)

$3(1)$

$15(2)$

8 (1)

$11(1)$

$17(2)$

$16(2)$

Slower growth of toenails (self-reported

$42(4)$

Shiny skin of legs

$52(5)$

$15(2)$

Complaints of disrupted sleep

Values are expressed as the mean \pm SD and or as $\mathrm{n}(\%)$. SD, standard deviation. 
Table II. Comparison of evaluation of obstructive lesions of the internal carotid artery using different imaging modalities.

\begin{tabular}{|c|c|c|c|c|c|c|c|}
\hline \multirow{3}{*}{$\begin{array}{l}\text { Obstructive } \\
\text { lesion parameters }\end{array}$} & \multicolumn{7}{|c|}{ Diagnostic modality adopted } \\
\hline & \multirow{2}{*}{$\begin{array}{l}\text { Invasive catheter } \\
\text { angiography } \\
(n=939)\end{array}$} & \multicolumn{3}{|c|}{$\begin{array}{l}\text { Color-coded duplex } \\
\text { sonography }(n=998)\end{array}$} & \multicolumn{3}{|c|}{$\begin{array}{l}\text { Magnetic resonance } \\
\text { angiography }(n=998)\end{array}$} \\
\hline & & Value & P-value ${ }^{a}$ & q-value ${ }^{a}$ & Value & P-value ${ }^{a}$ & q-value ${ }^{a}$ \\
\hline Normal $(0 \%)$ & $66(7)$ & $89(9)$ & $<0.0001$ & 4.144 & $59(6)$ & $<0.0001$ & 7.301 \\
\hline$<50 \%$ stenosis & $780(83)$ & $809(81)$ & & & $797(80)$ & & \\
\hline $50-69 \%$ stenosis & $65(7)$ & $38(4)$ & & & $77(8)$ & & \\
\hline $70-99 \%$ stenosis & $9(1)$ & $41(4)$ & & & $40(4)$ & & \\
\hline $\begin{array}{l}\text { Occlusion (no flow } \\
\text { detected; } 100 \% \text { ) }\end{array}$ & $19(2)$ & $21(2)$ & & & $25(2)$ & & \\
\hline
\end{tabular}

Values are expressed as $\mathrm{n}(\%) .{ }^{\mathrm{a} C}$ Comparison with invasive catheter angiography. The degree of stenosis was defined as per the Warfarin-Aspirin Symptomatic Intracranial Disease methodology under consultation of a neuroradiologist (25 years of experience).

Table III. Distribution of intracranial stenosis in the other intracerebral arteries assessed.

\begin{tabular}{lccc}
\hline Artery & $\begin{array}{c}\text { Invasive catheter } \\
\text { angiography }(\mathrm{n}=939)\end{array}$ & $\begin{array}{c}\text { Color-coded duplex } \\
\text { sonography (n=998) }\end{array}$ & $\begin{array}{c}\text { Magnetic resonance } \\
\text { angiography (n=998) }\end{array}$ \\
\hline $\begin{array}{l}\text { Internal carotid artery } \\
\text { Petrous segment }\end{array}$ & $7(1)$ & $8(1)$ & $9(1)$ \\
Cavernous segment & $7(1)$ & $8(1)$ & $9(1)$ \\
Cerebral segment & $4(0.4)$ & $5(0.5)$ & $3(0.3)$ \\
Vertebral artery & $15(1.5)$ & $14(1)$ & $13(1)$ \\
Anterior cerebral artery & $13(1)$ & $15(1.5)$ & $14(1)$ \\
Middle cerebral artery & & & $40(4)$ \\
M1 segment & $45(5)$ & $40(4)$ & $41(4)$ \\
M2 segment & $39(4)$ & $4(0.4)$ & $4(0.4)$ \\
Basilar artery & $5(0.5)$ & $0(0)$ & $0(0)$ \\
Posterior communicating artery & $1(0.1)$ & $1(0.1)$ & $1(0.1)$ \\
Posterior cerebral artery & $1(0.1)$ & & \\
\hline
\end{tabular}

Values are expressed as $\mathrm{n}(\%)$.

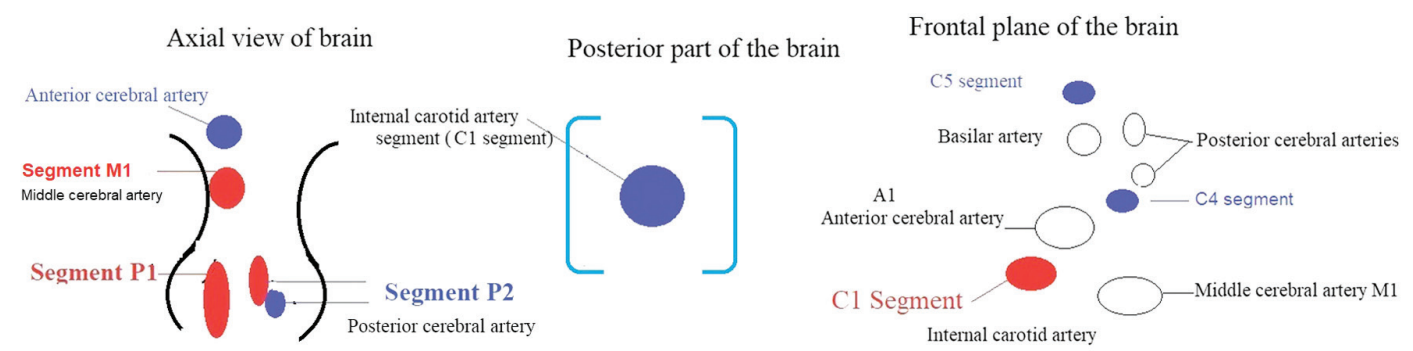

Figure 1. Regions of interest for transcranial color-coded duplex sonography.

Interobserver reliability. The quality of the acoustic window was categorized as excellent (1,550-1,300 HU), intermediate (1,299-1,150 HU) and poor ( $\leq 1,149 \mathrm{HU})$, and $<1,000 \mathrm{HU}$ was considered to indicate transtemporal window insufficiency. Color-coded duplex sonography had fewer readers' errors than invasive catheter angiography $(\mathrm{P}<0.0001 ;$ Table IV).

Diagnostic parameters. MRA $(\mathrm{P}=0.390)$ and color-coded duplex sonography $(\mathrm{P}=0.484)$ detected the same number of 


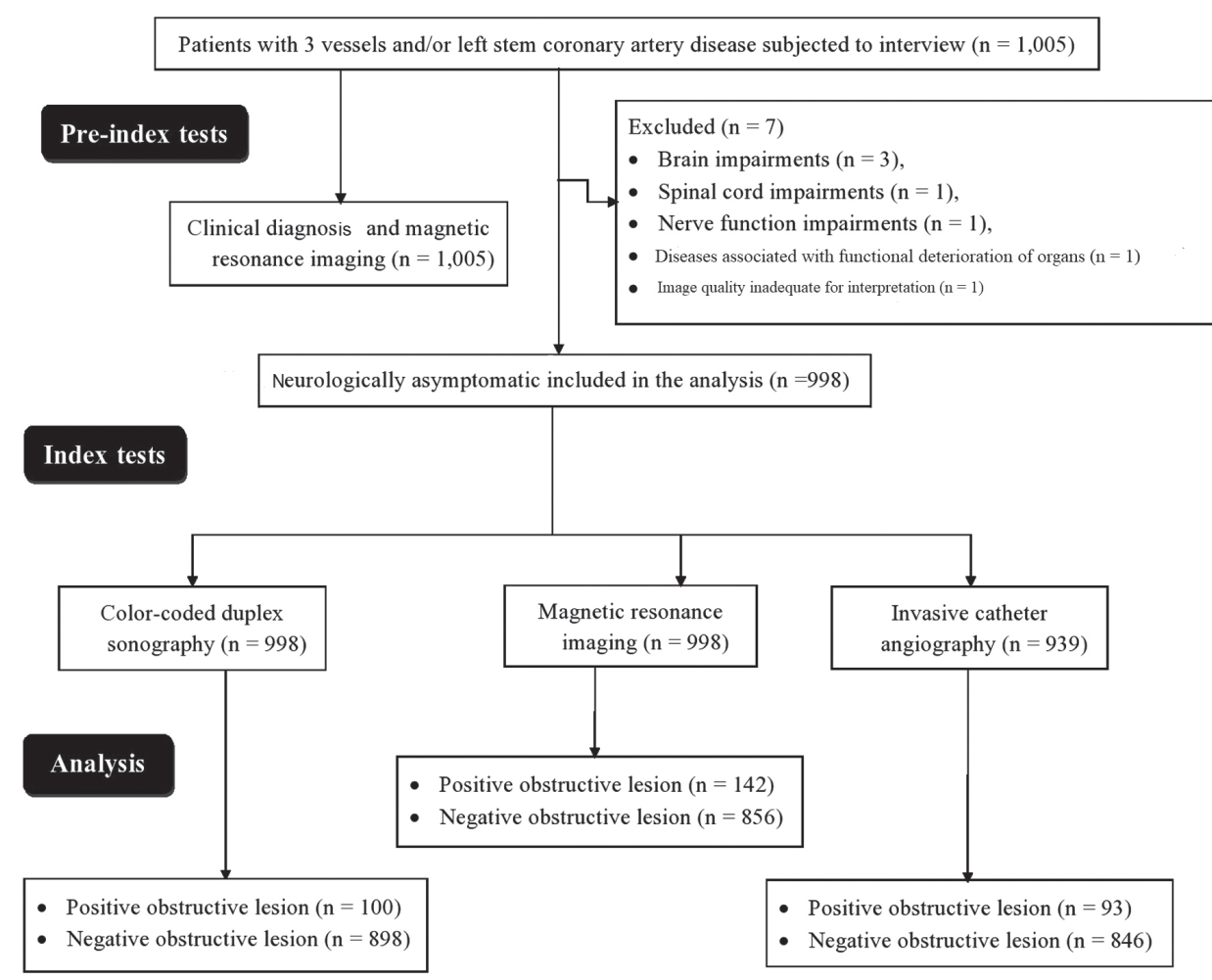

Figure 2. Flow diagram of the study.

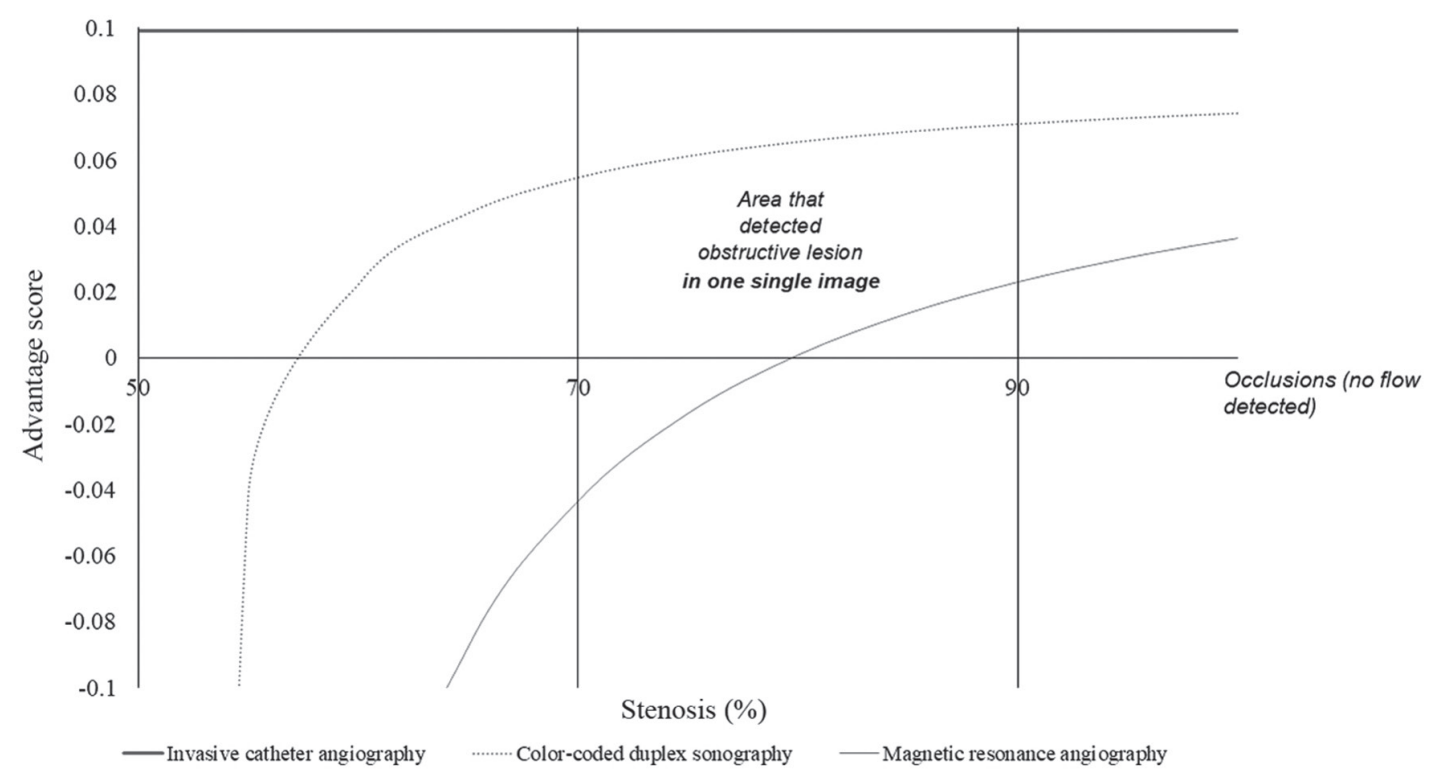

Figure 3. Clinical decision-making curve. The degree of stenosis was defined according to the Warfarin-Aspirin Symptomatic Intracranial Disease methodology under consultation of a neuroradiologist (25 years of experience).

true-positive obstructive lesions with invasive catheter angiography set as the gold standard. As compared to invasive catheter angiography, the sensitivities of color-coded duplex sonography and MRA were 0.935 and 0.957 and the accuracies were 0.920 and 0.974 , respectively (Table V).

Clinical decision-making analysis. Color-coded duplex sonography was able to detect an obstructive lesion in one single image for ICAs with $\geq 57 \%$ stenosis, while MRA was capable of detecting an obstructive lesion in one single image for ICAs with $\geq 80 \%$ stenosis. For ICAs that had $<57 \%$ of stenosis, color-coded duplex sonography had a risk of overdiagnosis and for ICAs that had $<80 \%$ of stenosis, MRA had a risk of overdiagnosis (Fig. 3).

Cost. Color-coded duplex sonography was the cheapest of the 3 methods applied, and the cost per patient was significantly lower than that of invasive catheter angiography $(\mathrm{P}<0.0001$, $\mathrm{q}=419.81)$ and MRA $(\mathrm{P}<0.0001, \mathrm{q}=330.21$; Fig. 4). 
Table IV. Mean reader differences.

\begin{tabular}{|c|c|c|c|c|c|}
\hline \multirow[b]{2}{*}{ Parameter } & \multirow{2}{*}{$\begin{array}{l}\text { Invasive catheter } \\
\text { angiography }(\mathrm{n}=939)\end{array}$} & \multicolumn{2}{|c|}{$\begin{array}{l}\text { Color-coded duplex } \\
\text { sonography }(n=998)\end{array}$} & \multicolumn{2}{|c|}{$\begin{array}{l}\text { Magnetic resonance } \\
\text { angiography }(\mathrm{n}=998)\end{array}$} \\
\hline & & Value & P-value & Value & P-value \\
\hline Number of readers & 8 & 7 & N/A & 5 & N/A \\
\hline Number of readers' errors & $47(5)$ & $9(1)$ & $<0.0001$ & $31(3)$ & 0.037 \\
\hline
\end{tabular}

Values are expressed as $\mathrm{n}$ or $\mathrm{n}(\%) .{ }^{\mathrm{a}}$ Comparison with invasive catheter angiography. N/A, not applicable.

Table V. Diagnostic parameters.

\begin{tabular}{|c|c|c|c|c|c|}
\hline \multirow[b]{2}{*}{ Item } & \multirow{2}{*}{$\begin{array}{l}\text { Invasive catheter } \\
\text { angiography }(\mathrm{n}=939)\end{array}$} & \multicolumn{2}{|c|}{$\begin{array}{l}\text { Color-coded duplex } \\
\text { sonography (n=998) }\end{array}$} & \multicolumn{2}{|c|}{$\begin{array}{l}\text { Magnetic resonance } \\
\text { angiography }(n=998)\end{array}$} \\
\hline & & Value & P-value ${ }^{a}$ & Value & P-value ${ }^{a}$ \\
\hline True-positive obstructive lesion & $93(10)$ & $87(9)$ & 0.3900 & $89(9)$ & 0.4840 \\
\hline True-negative obstructive lesion & $846(90)$ & $778(78)$ & $<0.0001$ & $824(83)$ & $<0.0001$ \\
\hline False-positive obstructive lesion & $0(0)$ & $13(1)$ & 0.0003 & $53(5)$ & $<0.0001$ \\
\hline False-negative obstructive lesion & $0(0)$ & $120(12)$ & $<0.0001$ & $32(3)$ & $<0.0001$ \\
\hline Sensitivity & 1 & 0.935 & $<0.0001$ & 0.957 & $<0.0001$ \\
\hline Accuracy & 1 & 0.920 & $<0.0001$ & 0.974 & $<0.0001$ \\
\hline
\end{tabular}

Values are expressed as $\mathrm{n}(\%)$ or ratio. A reduction in diameter of $\geq 50 \%$ was considered to indicate a positive obstructive lesion. ${ }^{\mathrm{a}} \mathrm{Comparison}$ with invasive catheter angiography. N/A, not available.

Complications. After invasive catheter angiography, three patients suffered injuries to the catheterized artery, one patient had an irregular heart rhythm, two patients reported allergic reactions to the medications used during the procedure, one patient had increased bleeding and one patient suffered an infection.

\section{Discussion}

In the present study, color-coded duplex sonography, MRA and invasive catheter angiography were used to assess the degree of stenosis in patients with coronary artery disease with satisfactory sensitivity and accuracy, as well as manageable readers' errors and diagnostic costs. The results were consistent with those of previous prospective studies $(1,5)$. Catheter angiography provides excellent visualization but it is risky, invasive, expensive (15) and requires contrast agent injection (7). In addition, invasive catheter angiography has a risk of false-negative predictions in the chronic stage of the disease or segmental stenosis in young patients (16). For MRA, the use of 3.0 and 1.5 Tesla been debated, e.g. 1.5 Tesla MRA has higher sensitivity and accuracy than 3.0 Tesla MRA but 3.0 Tesla has a higher spatial resolution and signal-to-noise ratio (17). All in all, the present study was successful in the pre-operative evaluation of risk factors for coronary artery bypass grafting surgery.

Compared to invasive catheter angiography, the color-coded duplex sonography detected a similar number of

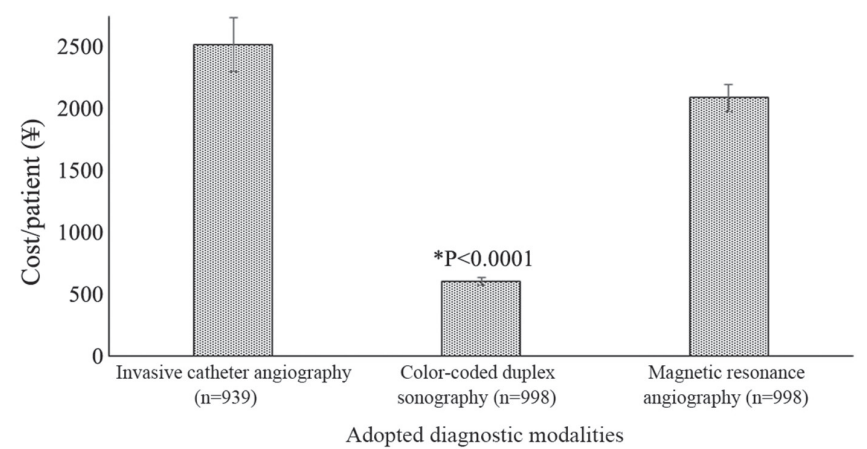

Figure 4. Cost of the diagnostic modalities adopted. Values are expressed as the mean \pm standard deviation.

obstructive lesions ( 93 vs. $100, \mathrm{P}=0.363$ ), but MRA reported higher numbers of obstructive lesions (142 vs. 100, $\mathrm{P}=0.019$ ). 3.0 Tesla MRA imaging has limitations in the detection of decreased velocity of inflowing blood (17). Therefore, MRA should be applied to detect occluded lesions, while detection of the degree of stenosis in lesions using this technique remains challenging. The higher numbers of positive obstructive lesions detected indicated a reduced accuracy of 3.0 Tesla MRA.

The present study reported significantly higher numbers of false-positive obstructive lesions for MRA than color-coded duplex sonography (53 vs. $13, \mathrm{P}<0.0001$ ). These results were not in line with those of one previous study (17) but were 
consistent with those of retrospective studies $(15,18)$. 3.0 Tesla MRA image resolution or image artifacts are responsible for the false-positive results (19), particularly for vasculitis (16). The present study reported that MRA overestimates the prevalence of incidental aneurysms in patients with coronary artery disease.

In the present study, a clinical decision-making curve indicated that color-coded duplex sonography has a higher working area and a lower risk of overdiagnosis than MRA. These results study were in line with those of a previous prospective study (5). Color-coded duplex sonography is a more suitable approach for the evaluation of cerebrovascular diseases than MRA.

Of note, the present study had several limitations, for instance, all patients included were Chinese. Due to certain diseases, the condition is more prevalent in Asians and the results may not be completely generalized to Caucasian patients. The sensitivity (0.935) of color-coded duplex sonography was lower than that of MRA (0.957). Insufficient transcranial acoustic bone windows (20) and tandem stenosis (5) were responsible for the lower sensitivity of color-coded duplex sonography in the present study, while MRA provided clearer images with lower blood fluctuation of arteries (17).

In conclusion, invasive catheter angiography, MRA and color-coded duplex sonography were used to assess the risk for coronary artery bypass grafting surgery. Invasive catheter angiography is risky, inaccurate for segmental stenosis in young patients ( $\leq 45$ years) and expensive. Color-coded duplex sonography was able to detect an obstructive lesion in one single image for ICAs with $\geq 57 \%$ stenosis, while MRA was only capable of detecting an obstructive lesion in one single image for ICAs with $\geq 80 \%$ stenosis. Color-coded duplex sonography is a reliable method for the detection of intracranial stenosis in patients with coronary artery disease.

\section{Acknowledgements}

Not applicable.

\section{Funding}

No funding was received.

\section{Availability of data and materials}

The datasets used and/or analyzed during the present study available from the corresponding author on reasonable request.

\section{Authors' contributions}

All authors had read and approved the manuscript prior to submission for publication. LX was the project administrator and contributed to the conceptualization, formal analysis and literature review of the study. WC contributed to resources, software and literature review of the study and drafted and edited the manuscript for intellectual content. HW contributed to resources, formal analysis, data curation and literature review of the study. The authors agree to be accountable for all aspects of the work, ensuring integrity and accuracy.

\section{Ethics approval and consent to participate}

The protocol (no. LCH/CL/11/15 dated 1 January 2015) of the study was approved by the Luoyang Central Hospital Affiliated to Zhengzhou University human ethics committee (Luoyang, China). Informed consent forms were signed by all participants, which included consent for biopsy, radiology and to an additional procedure for research purposes only. The study adhered to the law of China, the STrengthening the Reporting of OBservational studies in Epidemiology statement and the Declaration of Helsinki (version from 2008).

\section{Patient consent for publication}

Not applicable.

\section{Competing interests}

The authors declare that they have no competing interests.

\section{References}

1. Valaikiene J, Ryliskyte L, Valaika A, Puronaite R, Dementaviciene J, Vaitkevicius A, Badariene J, Butkuviene I, Kalinauskas G and Laucevicius A: A high prevalence of intracranial stenosis in patients with coronary artery disease and the diagnostic value of transcranial duplex sonography. J Stroke Cerebrovasc Dis 28: 1015-1021, 2019.

2. Bos D, van der Rijk MJ, Geeraedts TE, Hofman A, Krestin GP, Witteman JC, van der Lugt A, Ikram MA and Vernooij MW: Intracranial carotid artery atherosclerosis: Prevalence and risk factors in the general population. Stroke 43: 1878-1884, 2012.

3. Jin H, Peng Q, Nan D, Lv P, Liu R, Sun W, Teng Y, Liu Y, Fan C, Xing $\mathrm{H}$, et al: Prevalence and risk factors of intracranial and extracranial artery stenosis in asymptomatic rural residents of 13 villages in China. BMC Neurol 17: 136, 2017.

4. Mazighi M, Labreuche J, Gongora-Rivera F, Duyckaerts C, Hauw JJ and Amarenco P: Autopsy prevalence of intracranial atherosclerosis in patients with fatal stroke. Stroke 39: 1142-1147, 2008.

5. Valaikiene J, Schuierer G, Ziemus B, Dietrich J, Bogdahn U and Schlachetzki F: Transcranial color-coded duplex sonography for detection of distal internal carotid artery stenosis. Am J Neuroradiol 29: 347-353, 2008.

6. Baradaran H, Patel P, Gialdini G, Al-Dasuqi K, Giambrone A, Kamel $\mathrm{H}$ and Gupta A: Quantifying intracranial internal carotid artery stenosis on MR Angiography. Am J Neuroradiol 38: 986-990, 2017.

7. Chen J, Zhao B, Bu C and Xie G: Relationship between the hemodynamic changes on multi-Td pulsed arterial spin labeling images and the degrees of cerebral artery stenosis. Magn Reson Imaging 32: 1277-1283, 2014

8. Pu Y, Liu L, Wang Y, Zou X, Pan Y, Soo Y, Leung T, Zhao X, Wong KS and Wang Y; Chinese IntraCranial AtheroSclerosis (CICAS) Study Group: Geographic and sex difference in the distribution of intracranial atherosclerosis in China. Stroke 44: 2109-2114, 2013.

9. Liebeskind DS, Kosinski AS, Saver JL and Feldmann E; SONIA Investigators: Computed tomography angiography in the stroke outcomes and neuroimaging of intracranial atherosclerosis (SONIA) study. Interv Neurol 2: 153-159, 2014.

10. Duffis EJ, Jethwa P, Gupta G, Bonello K, Gandhi CD and Prestigiacomo CJ: Accuracy of computed tomographic angiography compared to digital subtraction angiography in the diagnosis of intracranial stenosis and its impact on clinical decision-making. J Stroke Cerebrovasc Dis 22: 1013-1017, 2013.

11. Ryoo S, Lee MJ, Cha J, Jeon P and Bang OY: Differential vascular pathophysiologic types of intracranial atherosclerotic stroke: A high-resolution wall magnetic resonance imaging study. Stroke 46: 2815-2821, 2015. 
12. Liu Q, Huang J, Degnan AJ, Chen S, Gillard JH, Teng Z and Lu J: Comparison of high-resolution MRI with CT angiography and digital subtraction angiography for the evaluation of middle cerebral artery atherosclerotic steno-occlusive disease. Int J Cardiovasc Imaging 29: 1491-1498, 2013.

13. Kochar M and Min JK: Physiologic assessment of coronary artery disease by cardiac computed tomography. Korean Circ J 43: 435-442, 2013

14. Fitzgerald M, Saville BR and Lewis RJ: Decision curve analysis. JAMA 13: 409-410, 2015.

15. Bash S, Villablanca JP, Jahan R, Duckwiler G, Tillis M, Kidwell C, Saver J and Sayre J: Intracranial vascular stenosis and occlusive disease: Evaluation with CT angiography, MR angiography, and digital subtraction angiography. Am J Neuroradiol 26: 1012-1021, 2005.

16. Ahn SH, Lee J, Kim YJ, Kwon SU, Lee D, Jung SC, Kang DW and Kim JS: Isolated MCA disease in patients without significant atherosclerotic risk factors: A high-resolution magnetic resonance imaging study. Stroke 46: 697-703, 2015.
17. Hirooka R, Ogasawara K, Inoue T, Fujiwara S, Sasaki M, Chida K, Ishigaki D, Kobayashi M, Nishimoto H, Otawara Y, et al: Simple assessment of cerebral hemodynamics using single-slab 3D time-of-flight MR angiography in patients with cervical internal carotid artery steno-occlusive diseases: Comparison with quantitative perfusion single-photon emission CT. AJNR Am J Neuroradiol 30: 559-563, 2009.

18. Cho YD, Lee JY, Kwon BJ, Kang HS and Han MH: False-positive diagnosis of cerebral aneurysms using MR angiography: Location, anatomic cause, and added value of source image data. Clin Radiol 66: 726-731, 2011.

19. Park S, Lee DH, Ryu C-W, Pyun HW, Choi CG, Kim SJ and Suh DC: Incidental saccular aneurysms on head MR angiography: 5 years' experience at a single large-volume center. J Stroke 16: 189-194, 2014.

20. Lee JD, Ryu SJ, Chang YJ, Hsu KC, Chen YC, Huang YC, Lee M, Hsiao MC and Lee TH: Carotid ultrasound criteria for detecting intracranial carotid stenosis. Eur Neurol 57: 156-160, 2007.

(7) $($ This work is licensed under a Creative Commons Attribution-NonCommercial-NoDerivatives 4.0 International (CC BY-NC-ND 4.0) License. 